\title{
Study on Chinese Rural Drinking Water Option and Its Pricing*
}

\author{
Jian-Fei Leng, Lu Li \\ Business School, Hohai University, Nanjing, China \\ Email: 1jf200209@gmail.com, lilu_nanjing@sina.com
}

Received September $21^{\text {st }}, 2012$; revised October $27^{\text {th }}, 2012$; accepted November $15^{\text {th }}, 2012$

\begin{abstract}
The problems of Chinese rural drinking water have existed for a long time and are deteriorating. Determining the price of rural drinking water is beneficial for solving these problems to some extent. Therefore, this article makes appropriate study on rural drinking water option and its pricing model. Based on the theories of options and water option, we make description on the connotation of rural drinking water option and its trading principle as well as main entities. In addition, on the basis of traditional Black-Scholes option pricing model and the actual situation of rural drinking water, we construct rural drinking water option pricing model from different aspects. With the guiding price of rural drinking water option, it can realize the optimum allocation of rural drinking water resource on the market.
\end{abstract}

Keywords: Rural Drinking Water; Water Option; Pricing Model

\section{Introduction}

At present, Chinese rural population has attained 650 million, according to the 2011 major macroeconomic data announced by China National Bureau of Statistics on January 17, 2012. The problems of Chinese rural drinking water exist for a long time, because of the large population, the growing problem of water pollution and many other constraints from society. With the advocacy of establishing water-saving society, it's necessary to construct water-conservation countryside. This is an important guarantee for peasants to acquire sufficient and safe drinking water timely and conveniently. Besides, it's also beneficial to improve quality of life and promote rural economic development. Although the problems of the water-wasting and low use efficiency exist widely, there is huge space for saving rural drinking water resources. However, it lacks effective distribution mechanism which can reduce the risk of water rights trading and achieve the rational allocation of rural drinking water. The study of rural drinking water option and its pricing is one of the important parts of the mechanism, which plays an indispensable role in alleviating current problem of rural drinking water. Water option is a financial derivative product, which settlement object is one or more water factors such as the price of water, rainfall, water demand and inflow et al. It's caused by hedging the risk of water supply and demand. Using mature options theories to manage the risk of water market has made it a new research focus.

With these backgrounds, this article attempts to study Chinese rural drinking water option and its pricing. Given the difficulty of data acquisition, this article only makes descriptive definition on related concepts of rural drinking water option and points out the principle and the transaction subject of its trading. Meanwhile, on the basis of traditional Black-Scholes

\footnotetext{
*Standards and Evaluation of Rural Water Conservancy Construction for Well-off Society. Project Supported by the Specialized Research Fund for the Public Causes of Ministry of Water Resources. (Grant No.: 201001037). Evaluation on Sustainable Development of Chinese Aquatic Ecological Environment. Project Supported by the Scientific Research Fundation of Philosophy and Social Sciences of the Jiangsu Higher Education Institutions of China.
}

pricing model and the characteristics of rural drinking water, the article tries to build the water option pricing model of rural drinking water. This will has constructive and pioneering significance on taking full advantage of our rural limited water resources and realizing the optimal allocation of it.

The paper is organized as follows: Section 1 is the introduction of the research. Section 2 discusses prior researches on rural drinking water option and option pricing. Section 3 describes the connotation of water option and rural drinking water option. Section 4 presents the option and its pricing of rural drinking water. Section 5 draws some conclusions.

\section{Prior Researches on Water Option}

\section{Option Pricing Model}

Option pricing model is the core option theory which experienced a long developing process. In 1900, French mathematician Louis Bachelier (1900) firstly put forward the option pricing model, while this model exists certain defects. Soon after, Sprenkle (1961) proposed the buyer option pricing formula, which assumed that the stock price is logarithmic distribution and there is fixed mean and variance. This model partly eliminates some of the defects of the Bachelier formula. Then, Samnelson (1965) established a European call option pricing model, this model considered that the expected rate of return of options and the stock are inconsistent due to the differences in risk characteristics. All these studies are the foundation of Black-Scholes model. In 1973, Black and Scholes (1973) firstly proposed the classic option pricing model in their famous paper Options Pricing and Corporate Debate. Hereafter, Merton (1982) published many papers about option pricing with important promotion in several aspect, which made a breakthrough in option pricing theory. Sing and Patel (2001) collected 2286 housing transaction data from 1984 to 1997 to estimate the value of delay option. Besides the classic Black-Scholes model, Cox, Ross and Robinstein (1979) put forward binomial option tree model. In the new era, based on those classic option pricing models, Han T. J. and Smit (2006) as well as Jiwook Jong 
(2007) considered many other influencing factors to establish many new model.

In China, Zhen Xiaoyin and Chen Jinxian (2000) analyzed the generation mechanism and the main features of the new options and then summarized the main types. Li shujin (2006), Zhou Jun (2007) and Mei Zhengyang (2002) et al., have made many researches on the option pricing model with stochastic interest rate and stochastic volatility.

\section{Water Rights and Water Option}

At present, there is little research on rural drinking water option and its transaction in developed countries. For the study of water rights trading, in 1994, Rosegrant Mark W. and Renato Gazmuri S. (1994) deemed that the allocation of water rights in market is an effective way to improve the configuration of water rights with the example of Chile, Mexico and California. Hereafter, Bauer Carl J. (1997), Pigram John J. (1999), Charles S. Sokile and Barbara van Koppen (2004) investigated different countries to study the transaction of water rights. Based on water law of Chile, Bauer Carl J. (1997) explored its water rights trading, besides, Pigram John J. (1999) studied water rights trading in Australia. In addition, Charles S. Sokile and Barbara van Koppen (2004) made the Tanzania Rufigi Basin as an experimental object, then they discussed the effects taken by local water rights management informal regulations on the water users. As to water option, there is still in its infancy. In recent years, Michelsen et al. (2000), Villenski (2002) and Ahmed Hafi et al. have made preliminary qualitative researches on water option from different angles and levels, all these studies are based on water market environment of developed countries as the background.

Zhang Yu (2002), Ge Yanxiang and Liu Weihua (2004) explored and studied water option from different levels, they combined ideas of futures market with water resources and took advantage of options system to make effective allocation of water resource. Jiang Jianyong and Xue Yi made Zhejiang agricultural water as study object, then they draw on ideas of options to design water rights trading derivatives, namely agricultural water option.

\section{Water Option Pricing}

Black-Scholes is a classic option pricing model which is widely used in many aspects all over the word. However, there is little reference can be found in other countries.

In China, Chen Jie and Xu Changxin (2006), Wang Huimin and Qiu lei et al. (2008) as well as Dai Tiansheng and Zhao Wenhui(2009), all of them have made related research. Chen Jie and Xu Changxin (2006) combined theory of options with water right trading, then they put forward water option trading pattern and determined water option pricing model according to the characteristics of fluctuations in the price of water rights. Wang Huimin and Qiu Lei et al. (2008) conducted a preliminary study on the basic content of water option and its pricing methods with the reality of our country's regimen and water market. With the example of eastern front of south-to-north water diversion, they verified the feasibility of such method and discussed the conditions of application of our water option trading in detail. In the same year, Qiu Lei and Wang Hui et al. (2008) still studied the eastern front of south-to-north water diversion, they used "Two part season-of-use price model" to make inter-provincial price of water pricing and used meanreversion model to simulate the underlying asset price of water of such options. Dai Tiansheng and Zhao Wenhui et al. (2009) conceived that assessing the value of water options was a key issue in water options trading. With the foundation of real options, they established evaluation model of water option's value and gave the analytical expression of the value of water rights, which provided an important basis of scientific decision-making for market participants and can effectively avoid risks.

\section{Comments on Prior Research}

From the prior researches we can see that there are few researches on the water option trading which introduced options pricing theory. Currently, the study of options pricing for water is still in its infancy and the research background is very narrow, most of study objects are the water market environment in developed countries. While in China, with the theories of options, many scholars have focused on water rights trading and trading pattern as well as water option pricing model. However, due to the limitations of macroeconomic conditions, the current related studies are all general qualitative introductions or a simple quantitative study with an experimental unit, while the study of rural drinking water is almost none. Therefore, this article tries to explore the water option and the pricing on rural drinking water in China with the object of rural drinking water, which makes up for the bank of studies in rural drinking water market to a certain extent.

\section{Basic Connotation of Water Option and Rural Drinking Water Option}

\section{Basic Connotation of Water Option}

\section{Basic Connotation of Water Option}

Water option is a standardized contract or agreement which stimulates that the option buyer has the right to buy a certain volume of water from the seller at a specific price within a specific time in the future and the option seller also has the right to sell the buyer a certain amount of water under the same condition. When requested to exercise the option, the water option seller is obliged to sell a certain amount of water prescribed by the contract price. However, in order to acquire the right to buy water, the option buyer need to pay a certain premium to the seller as compensation, this premium is often referred as water option price. Actually, water option is a financial derivative product which settlement object is one or more factors. Generally speaking, financial options can be divided into call options and put options, so can water option. The holder of call water option has the right to purchase the specified water rights in the determined time or period with pre-agreed price, while the holder of put water option has the right to sell the specified water rights in the determined time or period with pre-agreed price. In the contract of water option, the price reached by the two parties of transaction is called the exercise price or strike price. The date of water option implementation is called maturity date, exercise date or expiry date.

American water option can be executed within the validity period at any time, while the European water option only can be executed on the expiry date. Therefore, water option can be divided into four sorts. They are call European option, put European option, call American option and put American option. The 
holder of call European water option is entitled to purchase the specified water rights on the due date. The holder of put European water option has the right to sell the specified water rights with exercise price on the due date. The holder of call American water option can buy the specified water rights with exercise price before the maturity date. And the holder of put American option call dibs on selling the specified water rights with exercise price before the expiry date. American option is usually more difficult to analyze than European option, and some of its properties are always derived by the nature of European-style options.

\section{The Different Features of Water Option Compared with Financial Option}

In the financial market, financial option is often regarded as a significant tool of avoiding the risks of commodity market and an important complement to cash market.

In contrast with the cash market, financial option can evade risks of price and investment financing effectively with its advantages such as price discovery advantage, hedging advantage and risks diversification advantage et al. However, in terms of water resources, water option has its own uniqueness because of its special nature. These features mainly reflected in its trading purpose, underlying assets and execution condition.

1) Different purpose.

Financial option is primarily used to avoid price risk and the risk of investment and financing, while water option is used to avoid the risk of water supply and adjust the allocation of water resources. With the development of water market, the rule of the financial market can also be introduced into water market.

2) Different underlying asset.

In general, the underlying asset of financial option is a commodity price, while the underlying asset of water option is the price of water rights. The uniqueness of this price is determined by the particularity of water resources. Under the macro-control of China, the changing trend of the water price is very different from that of commodity price adjusted by the full market.

3) Different vesting conditions.

For financial option, the vesting condition of call option is when the commodity price of cash market is higher than the price stipulated in the option contract. While for water option, its vesting condition is when the supply of real-time water is lower than the water supply specified in the option contract.

4) Different exercise time.

Because the cycle of water use structural adjustment is longer than others, the option buyer should inform option seller the needs of exercise beforehand. Then, the water options seller can adjust water use timely and effectively.

5) Different mechanism of negotiation.

Water is affected largely by the uncertainty weather. In the contract, arbitration institution or a mechanism of re-negotiation should be agreed in advance so that it can avoid uncontrollable situation and unnecessary waste of water resources by negotiating and amending the content of contract.

6) Different configuration.

The introduction of water option configuration is a beneficial supplement to the water market. Due to the complication of water rights trading formalities, the introduction of water option can facilitate water rights trading and increase the use value of water.

\section{Rural Drinking Water Option}

\section{Connotation of Rural Drinking Water Option}

Rural drinking water option is a specific use of water option in rural areas. It's a standardized contract or agreement between water users which stimulates that the option buyer has the right to buy a certain volume of water from the seller at a specific price within a specific time in the future and the option seller also has the right to sell the buyer a certain amount of water under the same condition.

Rural drinking water option can also be divided into call option and put option, according to the actual situation of the characteristics of rural drinking water and water users. Call option of rural drinking water is a call option contract formulated with the system of water option trading. The underlying asset of the option is the rights of rural drinking water which should be negotiated when signed contract between the two parties, rather than change with the water price in the market. According to the characteristics of rural drinking water, the maturity date of rural drinking water option stipulated in the contract can have an appropriate extension. As to the price of option contract, it is the fee that water users should pay to the empty side in order to get the rights of buying drinking water option. Generally speaking, the royalty is much lower than the price in water rights market.

After buying the contract of rural drinking water option in accordance with a certain exercise price, water users have right to ask the seller to give them specified amount of water rights with order execution price if they need, regardless the fluctuation of water rights price within the validity period of the contract. If the water users do not apply to exercise the rights in due date, the option contract should be abolished. Similarly, the basic elements in the contract of put rural drinking water option are accordance with that of call option. The difference is that the holders of put option have right to sell their drinking water option in the put option contract.

With the implementation of option system, there are two methods for drinking water option. One is that water users can buy a call option with a lower price through selling water rights, and the price is so called premium. The other one is that water users can purchase put option while holding water rights as well. The option design of rural drinking water can not only reduce the market risks of water users but also regulate the rational allocation of rural drinking water resources effectively at the same time.

\section{Principles of Rural Drinking Water Option Trading}

The same with ordinary financial option trading, rural drinking water option need to follow certain principles when entering into a transaction.

\section{1) Principle of efficiency.}

Efficiency principle of rural drinking water option must come first. This principle requests that the value of rural drinking water rights must be converted to the large use of water resources value in the transaction. At the same time, it also should promote conservation of rural drinking water resources and encourage water use efficiency.

2) Principle of not prejudicing the third party's interests.

The trade of rural drinking water option will produce the ad- 
justment of interest between the two parties. Besides, the related rights and obligations should occur between buyers and sellers and not cause any loss of the third party. That is to say rural drinking water option trading should not make injury of the third party's interests as a precondition. Otherwise, the third party has the right to proceed in accordance with legal procedures.

3) Principle of ecological environment protection.

Ecological environment is an important factor related to Chinese people's livelihood and the development of its national economy. Furthermore, the countryside is the strong backing of economic development. Therefore, we must take ecological environment protection into consideration when carrying out the trade of rural drinking water option.

4) Principle of sustainable use.

Water resource is an important strategic resource of national economic development which can't be renewable. Once the water resources is contaminated, it will certainly affect the harmony between human and nature, what's important is that it will have a direct impact on the ability of human survival and development. Consequently, we must adhere to the principle of sustainable development in the procedure of rural drinking water option trading. Meanwhile, we should try to make water resources development, utilization, protection and management development harmoniously.

5) Principle of ability to pay and voluntary of water users.

Trade of rural drinking water option is mainly to regulate drinking water resources between farmers. The deed will make a reasonable allocation of water resources as well as improving water use efficiency. Therefore, during the transaction of rural drinking water option, we should consider the ability to pay of farmers and make a reasonable transaction price. Meanwhile, we shouldn't force farmers to trade in order to ensure the effectiveness of rural drinking water option trading, so the voluntary of water users must be taken into account.

6) Principle of government regulatory.

The prominent position of government regulatory in water option trading is determined by the public properties of water resources, it's also a necessity of eliminating government need to strengthen power of supervision in the transaction of rural drinking water option, such as building related legislation system, understanding rules of rural drinking water option, clearing transaction-related powers, duties and responsibilities. At the same time, government regulatory must be public and transparent so that it can ensure the fairness of such regulatory.

\section{Study on Option and Its Pricing of Rural Drinking Water}

\section{The Basis of Pricing Model}

\section{Option Pricing Model}

Currently, there are two widely used option pricing models. The first one is called binomial option tree model, a simplified treatment to the changes of underlying asset value base on dynamic programming method. This model is intuitive and has great flexibility applied to any of the underlying asset. No matter what option there is, this model can be used to define the price. Furthermore, this model can also apply to option pricing in the market environment and trading conditions change over time. The traditional binomial model is based on neutral risk and no arbitrage principles. The single-phase binomial model is

$$
\mathrm{C}=\frac{p \mathrm{C}_{\mathrm{U}}+(1-p) \mathrm{C}_{d}}{1+r}=p\left(\frac{\mathrm{C}_{u}}{1+r}\right)+(1-p)\left(\frac{\mathrm{C}_{d}}{1+r}\right)
$$

where $p=\frac{1+r-d}{u-d}$.

In the equation, $\mathrm{C}$ is the price of European call option, at the end of the first period the price of call option will either rise to $\mathrm{C}_{u}$ or fall to $\mathrm{C}_{d}, r$ is risk-free interest rate. Based on the single-phase binomial model, the n-phase binomial model can be deduced as

$$
\mathrm{C}=\frac{\sum_{j=0}^{n} \frac{n !}{j !(n-j) !} p^{j}(1-p)^{n-j} \max \left[0, \mathrm{Su}^{j} \mathrm{~d}^{n-j}-\mathrm{X}\right]}{(1+r)^{n}}
$$

The other pricing model is called Black-Scholes model, which is by means of mathematical tool of partial differential equations and the method of mathematical statistics to price the option. It's an extension of the binomial pricing model and a cornerstone of modern financial economic theory and financial theory. For the pricing of fair value option which remaining validity is more than two months and does not pay dividends, there is a positive effect on it. For the high value-added or highly impaired option, however, there is an obvious bias. Especially, the more close to the maturity date, the greater the option valuation error will be. The equation of Black-Scholes model will be introduced in detail in the theoretical basis of option pricing.

\section{Theoretical Basis of Option Pricing}

The most famous option pricing model of financial engineering is B.-S. pricing model, the theoretical basis of this article. In 1973, Black, F. and Scholes, M. J. (1973) [16] of American University of Chicago put forward the B.-S. model and made detail discussion on pricing of stock option, which is a great breakthrough of option pricing theory. In general, the assumptions of Black-Scholes model including the following factors. Firstly, the change of underlying asset price should abide by generalized Wiener Process, that is to say, the price of underlying asset follows a lognormal distribution. Secondly, using total income to oversell derivative assets is allowed. Thirdly, there is no transaction costs and tax and do not exist risk-free arbitrage opportunities. The last assumption is that risk-free interest rate is a constant and all maturities are the same. With the premise of these assumptions, we can obtain Black-Scholes differential equation of derivative asset price.

$$
\frac{\partial \mathrm{P}(x, t)}{\partial t}-r \mathrm{P}(x, t)+r x \frac{\partial \mathrm{P}(x, t)}{\partial x}+\frac{1}{2} \sigma^{2} x^{2} \frac{\partial^{2} \mathrm{P}(x, t)}{\partial x^{2}}=0
$$

where $\mathrm{P}(x, t)$ is the value of call option at time $t$ with the underlying asset price $x, r$ is risk-free interest rate. $\sigma^{2}$ represents the volatility of the underlying asset price. $T$ is the validity of the option. $\mathrm{K}$ is exercise price. And in the equation, $\mathrm{P}(x, \mathrm{~T})=\max \{0, x-\mathrm{T}\}, x>0$.

Then, we can obtain the pricing formula of call European option by solving the Black-Scholes partial differential equation.

$$
\mathrm{P}(x, t)=x \Phi\left(d_{1}(t)\right)-\mathrm{K} \Phi\left(d_{2}(t)\right) \mathrm{E}[-r(\mathrm{~T}-t)]
$$

In the equation, $\Phi\left(d_{1}(t)\right)$ and $\Phi\left(d_{2}(t)\right)$ are the stan- 
dardized cumulative normal distribution function.

$$
d_{1}(t)=\frac{\ln \left(\frac{x}{\mathrm{~K}}\right)+\left(r+\frac{\sigma^{2}}{2}\right)(\mathrm{T}-t)}{\sigma \sqrt{\mathrm{T}-t}}, d_{2}(t)=d_{1}(t)-\sigma \sqrt{\mathrm{T}-t}
$$

Similarly, put European option is the following one.

$$
\mathrm{P}(x, t)=x \Phi\left(-d_{1}(t)\right)+\mathrm{K} \Phi\left(-d_{2}(t)\right) \mathrm{E}[-r(\mathrm{~T}-t)]
$$

\section{Pricing Model of Chinese Rural Drinking Water Option}

\section{Assumptions of Rural Drinking Water Option}

By comparison with general merchandise, water resource has certain characteristics. In addition to the market mechanism, water resource is also affected by many factors, such as the national macro-control and precipitation. Rural drinking water option is similar to European non-arbitrage option and there is no transaction costs to both sides of option trading. Besides, it is also assumed that water market is a perfectly competitive market and the risk is neural. Therefore, we must do hypothesis on the basis of Black-Scholes model, otherwise it will lead to considerable error in the procedure.

There is a certain relationship between the assumption of rural drinking water option and that of basic option. Rural drinking water option is the specific use of basic option in rural drinking water. All the assumptions of basic option apply to rural drinking water. As the rural drinking water has its own characteristics, the fowling assumptions of rural drinking water are based on that of basic option with the characteristics of rural drinking water.

1) No arbitrage opportunities.

Water resource is both a public resource and a natural resource which easily forms a natural monopoly due to the objective reasons of space. In order to prevent the monopoly in the rural drinking water option trading and ensure the use efficiency of water resource, both our nation and local government should make limitations to the transaction of water rights, preventing behalf of arbitrage in water rights transaction. Therefore, there is no arbitrage opportunity in rural drinking water option trading.

2) Price of rural drinking water abides by unequal jump random process.

At present, water market is not a completely efficient market and rural drinking water market is more imperfect. The reflection of water price information on rural drinking water market is insensitivity. Only when external information has a certain degree effect on the transaction of rural drinking water rights, can decision-makers amend water price, otherwise, the price of water will maintain the original form and not change. Therefore, the price of rural drinking water has the characteristic of unequal jump, the change of rural drinking water price can be either positive jump or negative jump and this magnitude of jump is random.

3) No dividend payment.

There is no dividend issued in the process of rural drinking water option trading.

4) Compound option.

The investment entities of rural drinking water rights have the right to choose during the transaction of water rights. In the investment decision-making process of water rights, there in- volves a number of decisions and each decision will affect the next decision-making. The transaction of rural drinking water option is also an issue of multi-period decision-making, so it's a compound option.

5) No transaction costs.

Transaction of rural drinking water option includes many kinds of costs, such as costs of surveys and information collection, costs of option value discovery, costs of signing option contract, costs of prior development of trading rules and costs of subsequent implementation of management, supervision and protection. Since water resource is public resource, the state will bear costs of prior development of trading rules and subsequent implementation of management, supervision and protection. For traders, they only should be responsible for very little transaction costs of each. Therefore, in the study of this article, it can be approximated seemed as no transaction costs.

6) Water resource market is perfectly competitive and the risk is neutral.

\section{Pricing Model of Rural Drinking Water Option}

Based on Black-Scholes pricing model and the particularity of rural drinking water trading, this article only discusses European option of rural drinking water and does not consider the American option. We can determine the pricing model of rural drinking water option based on theoretical basis of Black-Scholes pricing model without considering the transaction investor made before the maturity date. Assume that interest rate $r$ is constant and calculated based on one-year Treasury bill rate. As the average interest rate of funds gained by water rights traders, traders can borrow or lend funds freely through certain channels. Borrowing interest rate and loan interest rate are equally, all are risk-free interest rate. Assume change of rural drinking water price $\mathrm{P}$ follows Geometric Brownian Motion and the lognormal distribution. In addition, rural drinking water option is an option without arbitrage opportunities, and there is no transaction costs between the two sides of option. Meanwhile, water resource market is a perfectly competitive market and the risk is neutral. We can obtain the value of water option.

$$
\mathrm{W}=\mathrm{P} \mathrm{N}\left(d_{1}\right)-\mathrm{Ke}^{-r(\mathrm{~T}-t)} \mathrm{N}\left(d_{2}\right)
$$

where $\mathrm{P}$ is the average price of water in market on rural drinking water pricing day. $\mathrm{K}$ is exercise price. $r$ is risk-free interest rate. $t$ is current time. $\mathrm{T}$ is the maturity date of rural drinking water option. $\mathrm{N}\left(d_{1}\right)$ and $\mathrm{N}\left(d_{2}\right)$ are the cumulative normal distribution function of $d_{1}$ and $d_{2}$ respectively. $\sigma$ represents the volatility rate of water option price.

From the view of investor, option reflects the rights of investment choice or the value of investment opportunities in the future. We can regard the right to use of rural drinking water as a call option. Investors need not rush to decide whether to implement the water right immediately or not, they can decide whether to delay the investment of the water right by understanding the market further to improve their initial evaluation results on cash flow of each period project. Therefore, based on the theory of delay, it is available to acquire the pricing model of delaying rural drinking water option.

$$
\mathrm{E}=\left[\beta \mathrm{E}^{+}+(1-\beta) \mathrm{E}^{-}\right] \times \mathrm{N}(1+\gamma)
$$

In the equation, 


$$
\begin{array}{ll}
\mathrm{E}^{+}=\max \left(0, \mathrm{C}^{+}-\mathrm{I}^{\prime}\right) & \mathrm{E}^{-}=\max \left(0, \mathrm{C}^{-}-\mathrm{I}^{\prime}\right) \\
\mathrm{I}^{\prime}=(1+\gamma) \mathrm{I} & \beta=\frac{[(1+\gamma)-d]}{u-d}
\end{array}
$$

where E represents the current value of delaying rural drinking water option. I is required investment. $\mathrm{C}$ is net cash flow of the project during its implementation period. $\gamma$ is risk-free interest rate. $u$ and $d$ represent rising factor and falling factor respectively. $\beta$ is the adjustment coefficient.

According to the assumptions of pricing of rural drinking water option, drinking water option in rural areas can be regarded as a decision model of compound water option based on unequal jump compound water option. Option price of rural drinking water is divided into price of call European option and price of put European option. Order $\mathrm{T}$ as maturity date, zero-coupon bond with maturity date $\mathrm{T}$ is $\mathrm{B}(t, \mathrm{~T})$, price of rural drinking water rights is $\mathrm{P}(t) . \mathrm{B}(t, \mathrm{~T})$ and $\mathrm{P}(t)$ are subject to the following jump diffusion process.

$$
\begin{gathered}
\frac{d \mathrm{~B}(t, \mathrm{~T})}{\mathrm{B}(t, \mathrm{~T})}=r(t) d t+\delta(t, \mathrm{~T}) d \mathrm{~W}_{t}^{1} \\
\frac{d \mathrm{P}(t)}{\mathrm{P}(t)}=r(t) d t+\delta(t) d \mathrm{~W}_{t}^{2}+\int_{-1}^{+\infty} y(r(d y, d t)-\lambda m(d y) \mathrm{dt})
\end{gathered}
$$

Considering that current price of rural drinking water right is $\mathrm{P}(0)$, expectation is $\mathrm{E}$, maturity date is $\mathrm{T} \cdot \mathrm{C}(0, \mathrm{P}(0))$ is call European option price of rural drinking water with maturity date $\mathrm{T}$ and $\mathrm{B}(0, \mathrm{~T})$ is the price of zero-coupon bond with maturity date $\mathrm{T}$, the exercise price is $\mathrm{K}$. The call European option of exercise $\mathrm{K}$ is $C(t, \mathrm{P})$

$$
C(\mathrm{~T}, \mathrm{P}(\mathrm{T}))=(\mathrm{P}(\mathrm{T})-\mathrm{K})^{+}=(\mathrm{P}(\mathrm{T})-\mathrm{K}) \cdot I_{\{\mathrm{P}(\mathrm{T}) \geq \mathrm{K}\}}
$$

and, $x^{+}=\max \{x, 0\}, I_{A}(x)=\left\{\begin{array}{l}1, x \in A \\ 0, x \notin A\end{array}\right.$

$$
\begin{aligned}
& C(0, \mathrm{P}(0)) \\
& =\mathrm{E}^{\mathrm{Q}}\left[\mathrm{B}^{-1}(\mathrm{~T}) \mathrm{P}(\mathrm{T}) \mathrm{I}_{\{\mathrm{P}(\mathrm{T}) \geq K\}}\right]-\mathrm{KE}^{\mathrm{Q}}\left[\mathrm{B}^{-1}(\mathrm{~T}) \mathrm{I}_{\{\mathrm{P}(\mathrm{T}) \geq \mathrm{K}\}}\right]
\end{aligned}
$$

$\mathrm{Q}$ is the martingale measure. Make unit of account $P(t)$ to $\mathrm{Q}^{\mathrm{S}}$ and $B(t, \mathrm{~T})$ to $\mathrm{Q}^{\mathrm{T}}$, we can deduce the formula.

$$
\begin{aligned}
& C(0, \mathrm{P}(0)) \\
& =\mathrm{P}(0) \mathrm{Q}^{\mathrm{S}}(\mathrm{P}(\mathrm{T}) \geq \mathrm{K})-\mathrm{KB}(0, \mathrm{~T}) \mathrm{Q}^{\mathrm{T}}(\mathrm{P}(\mathrm{T}) \geq \mathrm{K})
\end{aligned}
$$

With calculating, we can got that

$$
\begin{aligned}
& \mathrm{Q}^{\mathrm{T}}(\mathrm{P}(\mathrm{T}) \geq \mathrm{K})=\sum_{n=0}^{\infty} \frac{\mathrm{e}^{-\lambda T(\lambda T)^{n}}}{n !} E\left\{N\left(d_{2}^{n}\right)\right\} \\
& \mathrm{Q}^{\mathrm{S}}(\mathrm{P}(\mathrm{T}) \geq \mathrm{K})=\sum_{n=0}^{\infty} \frac{\mathrm{e}^{-\lambda T(\lambda T)^{n}}}{n !} E\left[N\left(d_{1}^{n}\right) \mathrm{e}^{-\lambda T E\left(U_{1}\right)} \prod_{j=1}^{n}\left(1+U_{j}\right)\right]
\end{aligned}
$$

The pricing formula of call European option of rural drinking water is the following one.

$$
\begin{aligned}
C(0, \mathrm{P}(0))= & \sum_{n=o}^{\infty} \frac{\mathrm{e}^{-\lambda T}(\lambda T)^{n}}{n !} E\left[\mathrm{P}(0) N\left(d_{1}\right) \mathrm{e}^{-\lambda T E\left(U_{1}\right)} \prod_{j=1}^{n}\left(1+U_{j}\right)\right. \\
& \left.-K \mathrm{~B}(0, T) N\left(d_{2}\right)\right]
\end{aligned}
$$

where $\mathrm{P}(0)$ is current price of rural drinking water. $\mathrm{E}$ is expectation and $\mathrm{T}$ is maturity date. $C(0, \mathrm{P}(0))$ is call European option price of rural drinking water with maturity date $\mathrm{T} . \mathrm{B}(0, \mathrm{~T})$ is the price of zero-coupon bond with maturity date $\mathrm{T}$. The exercise price is $\mathrm{K} . \lambda$ is a constant and a process of intensity in Poisson distribution. $\gamma$ is risk-free interest rate, that is the growth rate of rural drinking water. $t$ is current time. $N(\cdot)$ represents cumulative probability distribution function of standardized normal distribution variables. $d n$ is the random part of price changes. $U_{j}(j \geq 1)$ is independent and identical distribution random sequences.

$$
\begin{gathered}
d_{2}=\left[\mathrm{n}\left(P(0) \mathrm{e}^{-\lambda T E\left(U_{1}\right)}\right) \prod_{j=1}^{n}\left(1+U_{j}\right)\right] /[K B(0, \mathrm{~T})] \\
-\frac{1}{2} \int_{0}^{T}\left[\delta^{2}(t, \mathrm{~T})+\sigma^{2}(t)\right] \mathrm{dt} / \sqrt{\int_{0}^{T}\left[\delta^{2}(t, \mathrm{~T})+\sigma^{2}(t) \mathrm{dt}\right]} \\
d_{1}=d_{2}+\sqrt{\int_{0}^{\mathrm{T}}\left[\delta^{2}(t, \mathrm{~T})+\sigma(t) \mathrm{dt}\right]}
\end{gathered}
$$

where $\sigma(t)$ is the criterion of continuous compounding rate of return of rural drinking water right price. $\delta(t, T)$ is the volatility of the price of water rights in rural drinking water. $\gamma(t)$ is the rate of return of rural drinking water right price, and $\lambda m d t$ represents the compensation measure of $\gamma(t)$.

Based on these pricing models of option under different situations, we can calculate the guiding price of rural drinking water option. The guiding price can conduct the transaction of rural drinking water option and optimize the allocation of rural drinking water. For the investors of rural drinking water resource, they can also judge the level of market price according to the price calculated by the model and decide to buy or sell water option, thus achieving the optimal allocation of water resource through market

\section{Conclusion}

Options are important financial derivatives, so water option has its own incomparable superiority during water rights trading. Establishing trading patterns of rural drinking water option can bring many advantages, such as perfecting current allocation of rural drinking water resource reasonably and effectively, improving the utilization of rural drinking water, reducing the contradictions brought by the uneven distribution of water resources and enhancing its value in use. Based on the traditional Black-Scholes pricing model, this article determines the pricing model of rural drinking water option without considering the transaction investors made before the option maturity date. Taking the effectiveness of investor decision-making into account, this article also builds pricing model of delaying option of rural drinking water. In addition, this article regards rural drinking water option as decision-making model of compound options and also establishes option pricing model of rural drinking water based on unequal jump compound options. With these pricing models of option under different situation and guiding price of rural drinking water option calculated according to the different needs, it can absolutely promote the allocation and the rational use of rural drinking water as well as making contribution to the further development of rural economy.

\section{REFERENCES}

Black, F., \& Scholes, M. J. (1973). The pricing of option and corporate 
liabilities. Journal of Political Economy, 81, 637-542.

Bauer, C. J. (1997). Bringing water markets down to earth: The political economy of water rights in Chile. World Development, 5, 639656. doi:10.1016/S0305-750X(96)00128-3

Chen, J., \& Xu, C. X. (2006). Options trading patterns of the water rights in China. Chinese Journal of Population Resources and Environment, 2, 42-44.

Dai, T. S., \& Zhao, W. H. et al. (2009). Evaluation model of water option value based on real options theory. Systems Engineering, 5, 67-71.

Ge, Y. X., \& Hu, J. L. (2004). Idea of deploying water resources of agriculture by using option system. Social Science of Shandong, 10, 49-51.

Hafi, A., Beare, S., Heaney, A., \& Page, S. (2005). Water options for environmental flows. ABARE Report.

Han, T. J. S., \& Lenos, T. (2006). Real options and games: Competition, alliances and other applications of valuation and strategy. Review of Financial Economics, 15, 95-112. doi:10.1016/j.rfe.2005.12.001

Jiang, J. Y., \& Xue, Y. (2008).The idea of agricultural water option trading in Zhejiang. Business Times, 23, 100-101.

Liu, W. H. (2004). Thoughts on the construction of futures and options trading water market. Water Resources Development Research, 6, 36-41.

Merton, R. C. (1982). Theory of rational option pricing. Bell Journal of Economics and Management Science, 4, 141-183. doi: $10.2307 / 3003143$

Michelsen, A., \& Young, R. (2000). Optioning agricultural water rights for urban water supplies during drought. American Journal of Agricultural Economics, 11, 1010-1020.

Pigram, J. J. (1999). Tradable water rights: The Australian experience.
Qiu, L., \& Wang, H. et al. (2008). Water option pricing model based on monte carlo-Eastern front of South-North water diversion. Statistics and Decision, 23, 61-64.

Rosegrant, M. W. R., \& Renato, G. S. (1994). Reforming water allocation policy through markets in tradable water rights: Lessons from Chile, Mexico and California. Washington DC: International Food Policy Research Institute.

Sokile, C. S., \& Koppen, B. (2004). Local water rights and local water user entities: The unsung heroines of water resource management in Tanzania. Physics and Chemistry of the Earth, 29, 1349-1356. doi:10.1016/j.pce.2004.09.010

Villenski (2002). Valuing multiple-exercise of options contracts: Methodology and application to water markets. American Agriculture Economic Association Annual Meeting, CO: Denver, 8.

Wang, H. M., Qiu, L. et al. (2008). Water option and its pricing model-Eastern front of South-North water diversion. Systems Engineering, 7, 45-51.

Zhen, X. Y., \& Chen, J. X. (2000). Study on Exotic option and its pricing model. Management Engineering Report, 14, 56-60.

Zhou, J., \& Gong, R. C. (2007). Variety exchange rate linkage option pricing formula on the condition of the model of stochastic interest rate. Statistics and Decision, 7, 142-143.

Zhang, Y., Qin, L. J., \& Jin, Y. H. (2002) Tentative plan of establishing south-north water market with the idea of futures market. Chinese Journal of Population Resources and Environment, 2, 57-60. 